
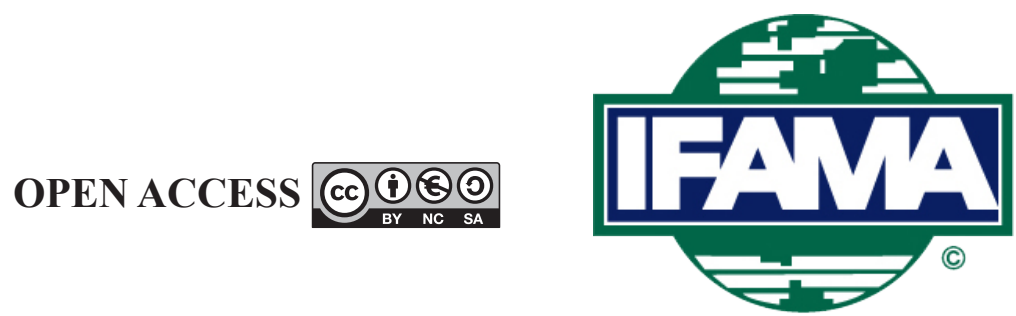

International Food and Agribusiness Management Review

Volume 21 Issue 8, 2018; DOI: 10.22434/IFAMR2017.0121

Received: 12 December 2017 / Accepted: 15 June 2018

\title{
Rationalizing apple growers' decision making in Germany - a utility based whole farm programming approach
}

\section{RESEARCH ARTICLE}

\author{
Maren B.K. Röhrig ${ }^{\oplus a}$, Bernd Hardeweg ${ }^{\mathrm{b}}$, and Wolfgang Lentz ${ }^{\mathrm{c}}$ \\ ${ }^{a}$ Research Associate, ${ }^{b}$ Researcher; Center for Business Management in \\ Horticulture and Applied Research, Institute of Horticultural Production Systems, \\ Leibniz University of Hanover, Herrenhäuser Straße 2, 30419 Hanover, Germany \\ 'Professor, Faculty of Agriculture/Environment/Chemistry, University of Applied \\ Sciences Dresden (HTW Dresden), Pillnitzer Platz 2, 01326 Dresden, Germany
}

\begin{abstract}
Commercial apple production is exposed to various sources of risks. This paper presents a normative utilityefficient programming (UEP) approach, calculating optimal farm plans for apple growers in two different regions of Germany. It takes weather-related quality and yield risks, as well as price risks into account. It is based on risk attitude and risk perception collected from a sample of 134 apple growers. After combining subjective estimates of the apple growers with relevant historical data, input data for the UEP-model were derived from Monte-Carlo simulations. The UEP-model determines optimal portfolios, consisting of combinations of apple varieties and risk management instruments. The results indicate that the degrees of risk aversion affect optimum farming strategies only to a minor extent. They also provide evidence that farmers would benefit from a combined frost-hail insurance, whereas the absence of frost irrigation systems may cause high yield-losses in the northern part of Germany.
\end{abstract}

Keywords: utility-efficient programming, risk aversion, risk management, crop insurance, certainty equivalent JEL code: Q13

\footnotetext{
(i)Corresponding author: roehrig@zbg.uni-hannover.de
} 


\section{Introduction}

Extreme weather events are the most critical and omnipresent source of risk in open field production. Adverse weather effects entail production risks due to yield and quality reductions as well as market risks which result from fluctuating volumes. Thus, appropriate risk management strategies are mandatory for an economically successful apple production. In this context, yield and quality are acknowledged as the main drivers for economic success in apple production (Bravin et al., 2009). However, effects of climate change on yield and quality risks in apple production are uncertain so far, which increases planning uncertainties. For example, simulation results for German apple orchards published by Hoffmann et al. (2012) indicate no considerable increase of blossom-damage due to late frosts in general terms, whereas the absolute increase of late frost risk depends on site-specific characteristics. As farm-specific adaptions to climate change are associated with additional costs, analysis on region-specific effects is required (Thomson et al., 2014).

For an evaluation of farming strategies, the economic assessment of a whole-farm strategy rather than of single farming options is suggested, since focusing on single crop investment decisions may lead to an overestimation of production and price risks. Furthermore, whole-farm planning can take competition for naturally constrained farm resources into consideration (Lehmann et al., 2013). With respect to time, resourceconstraints implemented in inter-temporal models allow for resource allocation over the whole planning period. Furthermore, a discount rate enables risk analysts to value current against future income streams (Janssen and van Ittersum, 2007; Pandey and Hardaker, 1995). For a comprehensive review of commonly applied planning models regarding perishable and non-perishable crops the reader is referred to Ahumada and Villalobos (2009).

Being a permanent crop, apple production requires long-term planning that considers the consequences of the initial investment decision over the whole economic life cycle of the orchard, which is aptly summarized by the net present value (NPV) as an indicator of profitability (Catalá et al., 2013). As the flexibility of adjustments regarding risk management instruments (RMI), i.e. sequential decision making, is restricted, risk management in apple production thus focuses on non-embedded risk, which means that apple growers have to decide a priori, at the beginning of the production period, how to lower their risks (Dorward, 1999; Hardaker et al., 2004:186-187).

Although the selection of appropriate apple varieties as well as the choice of the suitable RMI is non-trivial, this investigation tries to determine the most efficient strategies under risk by focusing on both factors. To our knowledge this study is the first to develop a decision support tool for a whole-farm strategy under risk, addressing apple production in Germany.

In order to create a prescriptive whole-farm model, a mathematical programming approach is applied. The model performs efficiency-analysis under the maximization of apple growers' utility, considering discounted cash flows for a production period of 20 years and taking weather-related risks into account. Additional constraints, i.e. the production area, farm diversification, as well as available protection systems against weather-related impacts for risk reduction, are further implemented. Referring to insurances, hail insurance (HI), which already exists, as well as a hypothetical combined frost-hail-insurance (FI sub \& HI sub) for transferring yield and quality risks outside the farm are considered.

\section{Literature review}

For the assessment of long term strategies the NPV, a proceeding of the dynamic capital budgeting, serves as the predominant evaluation technique in terms of profit maximization unless decisions are reversible. Recently, Catalá et al. (2013) maximized NPV with a mixed integer linear programming model when focusing on 20-year apple and pear production in Argentina (Catalá et al., 2013). However, the conventional NPV is calculated based on deterministic average values, addressing a risk neutral decision maker and multi-period 
returns are aggregated to a present value under loss of chronological reference. As a consequence, risk as well as liquidity constraints in the single periods are not taken into consideration (Bocquého and Jacquet, 2010).

An extension of dynamic capital budgeting is the real options approach (ROA). In contrast to the NPV, ROA is appropriate when investment-decisions are characterized by uncertainty, irreversibility and temporal flexibility, i.e. that the decision maker has the option to wait and defer the investment. The option to postpone the investment includes opportunity costs as an additional value, especially if returns are uncertain. If an investment is realized, this value can represent sunk costs, as it eliminates the option to realize alternative investments. In the case of postponing the investment, the loss of profit is captured. As ROA additionally accounts for these opportunity costs, the investment trigger shifts upwards (Dixit and Pindyck, 1994:6-9; Ihli et al., 2014). Supplementary to the option of deferment, other real options exist. For an overview please refer to Trigeorgis (1996:2-3). Wolbert-Haverkamp and Musshoff (2014) apply the traditional NPV as well as the ROA for explaining farmers' investment behavior when determining the effects arising from conversion of arable land to short rotation coppice. They find that ROA in comparison to NPV better explains farmers' inertia to convert rye into short rotation coppices (Wolbert-Haverkamp and Musshoff, 2014). Furthermore, Ihli et al. (2014) compare the ROA and the NPV criterion when predicting German farmers' investment and disinvestment behavior. Their results indicate that neither criterion exactly predicts experimentally observed decision making. However, the ROA is superior in explaining farmers' real behavior (Ihli et al., 2014). In our case we assume that the ROA provides no additional advantage, due to the following lines of thought. In apple production, insurances are not considered to serve as a disinvestment opportunity and hail nets (HN) as well as overhead irrigation for frost protection (IFP) are not easily reversible. Furthermore, these investments are supposed to be made during the establishment phase of the orchard and in consequence, temporal flexibility is not given. Furthermore, the installation of HN during the establishment phase reduces the establishment costs as the HN-construction may serve in addition as wire frame. Consequently, the NPV is supposed to provide a sufficient basis for the economic assessment of a whole-farm strategy in apple production.

As mentioned before, the traditional NPV disregards farmers risk attitude. Therefore, alternative concepts have been developed. One approach allowing portfolio choice in farm planning under risk is quadratic risk programming, also known as the expected value-variance framework (EV). It determines the efficient frontier, representing efficient portfolios, by maximizing the expected value or minimizing the variance (Hardaker et al., 2004:193; Ogurtsov et al., 2008). Applications of the EV in agricultural economics include the assessment of weather derivatives with respect to potential restrictions of water use. The study of Buchholz and Musshoff (2014) reveals that index-based weather insurance may compensate economical disadvantages resulting from water quotas as well as higher water prices in Germany. Bobojonov and Aw-Hassan (2014) also apply the EV for modelling the impact of climate change on arable farm income for countries in central Asia. Their results indicate that market liberalization could lead to an increase in revenues as well as a higher exchange of farm inputs and thus provide a strategy to cope with risks related to climate change (Bobojonov and Aw-Hassan, 2014).

Earlier investigations used MOTAD as a simplification of EV analysis. MOTAD is a linear programing model, approximating the EV efficient frontier, by maximizing the expected value of a performance indicator under reduction of the associated mean absolute deviation, which is included as a restriction (Hardaker et al., 2004:197-199). However, in recent years linear programming has lost its relevance as software is available to perform nonlinear programming (Lien et al., 2011). By applying MOTAD, Waibel et al. (2001) investigate the risk associated with the transformation of a conventional apple production into an organic one. They conclude that risk averse farmers should diversify as variety specialization leads to a higher expected annuity but also to an increase of the associated variance, i.e. risk (Waibel et al., 2001). With a related approach Mouron and Scholz (2008) evaluated farm income of twelve apple producing farms in Switzerland on basis of mean, standard deviation and skewness. Even though a programming model is not implemented in their investigation, the parameters allow them to draw several conclusions. They find that differences in management and predominantly high investment in pre-harvest hours, strongly influence the average income as well as the associated standard deviation. Interestingly, their correlation analysis reveals 
that the higher the average income, the lower the variability of income. Furthermore, one third of the farms reveal a low ability to compensate low income and mitigate the impact of catastrophic events (Mouron and Scholz, 2008).

Alternatively to EV, the subjective expected utility framework (EU) allows farm planning under risk, even if the data distribution is non-normal (Lien et al., 2011). This approach determines an optimal portfolio by maximizing the EU of a subject for a given risk attitude (Ogurtsov et al., 2008). Even if utility-efficient programming (UEP) applied for an extended time frame is judged to be sophisticated (Hardaker et al., 2004:238), Bocquého and Jacquet (2010) conduct a multi-period EU maximization approach, when assessing the economic effect of miscanthus- and switchgrass-adoption for a cereal farm in France. Furthermore, they apply the discounted utility (DU) framework where the discounted sum of instantaneous utilities is calculated. Contrary to NPV, this framework takes liquidity constraints during the production period into account and the decision makers preferences for regular incomes. Additionally, they implement a combination of EU and DU and address uncertainty as well as liquidity constraints simultaneously (Bocquého and Jacquet, 2010). Nonetheless, there are some critiques referring to the DU-model, as it is predominantly used because of its simplicity and its similarity to the traditional discount rate formula, although its empirical validity has never been confirmed (Frederick et al., 2002; Meyer, 2013).

Even though the EV method is widely used, it lacks theoretical justification. If one rejects the idea of increasing absolute and relative risk aversion with a growing wealth and thus the application of the quadratic utility function, the negative exponential (CARA) utility function represents an alternative. With CARA, normality assumptions become an essential prerequisite for consistency with EU (Lien et al., 2011; Ogurtsov et al., 2008). However, when focusing on catastrophic events, the assumption of normality does not hold. In addition, specification errors of the standard deviation may lead to an improper estimation of the distribution tails and risks might be over- or underestimated. Thus, in contexts where catastrophic risks are important, the EV is inappropriate (Ermoliev, et al., 2000; Ogurtsov et al., 2008). On the contrary and according to the developer of the mean-variance analysis, the above mentioned preconditions are not required for EV to hold and can rather be seen as sufficient conditions. Even under more relaxed assumptions, the EV can approximate the results of EU well (Markowitz, 2014). For example, Lien et al. (2011) demonstrate that the results of the EU and EV-framework show only minor and negligible deviations. Furthermore, their results indicate that risk modelling leads to unstable results due to sampling bias, if programming is only based on few observations (Lien et al., 2011).

As the whole-farm approach described in this paper leads to the evaluation of cash flows, which are relatively large in comparison to farmers' total wealth, the power utility function, implying constant relative risk aversion (CRRA), provides a more appropriate evaluation of risk preferences than CARA. Considering the insights provided by the discussed literature, we choose the EU framework for our analysis.

\section{Model approach}

A prescriptive multi-period utility-efficient programming model for an ex-ante optimization, considering uncertainty of prices and yields for sixteen years of full bearing is developed. The model considers the stochastic nature of annual cash flows $C F_{T C}$ for 20 years of orchard lifetime (T) by incorporating 100 drawings $\mathrm{C}$ for the variables yield, prices, costs and non-operating revenue from a Monte-Carlo simulation model for each activity, i.e. combination of variety, planting density and risk management measures (Röhrig et al., 2018). Since the respective drawings originate from identical iterations of the simulation model, stochastic dependencies between the variables are reflected in the cash flow data $C F_{T C}$. To maintain numerical feasibility, cash flows $C F_{T C}$ are scaled to units of $10,000 € z_{T C}$ (Equation 1), which are used as the argument for the utility function (Equation 2).

$$
z_{T C}=C F_{T C} / 10,000
$$


Since all drawings $C$ at $P=0.01$ are equally likely, the expected utility of the portfolio is calculated according to Equation 3 with the utility function presented in Equation 2. As mentioned above, we assume CRRA utility with initial wealth, which is set regionally specific at 160,000€ in the North and 75,000€ in the South, respectively. Relative risk aversion coefficients (hereafter $r$ ) regarding wealth $r_{r}(w)$ are set according to apple growers' risk attitude elicited via a farm profit-framed Holt and Laury lottery, originally pioneered by Holt and Laury (2002).

$$
U_{T C}=\left((\text { nonrisk } / 10,000)+z_{T C}\right)^{(1-r) \times 1 /(1-r)}
$$

Where

$U_{T C}=$ utility of total wealth per year T and draw C;

nonrisk = initial, non-stochastic wealth;

$z_{T C}=$ scaled, discounted cash flow;

$\mathrm{r}=$ relative risk aversion coefficient.

$$
E U Y_{T}=\sum_{C=1}^{100} p \times U_{T C}
$$

Where

$E U Y_{T}=$ expected utility per year $\mathrm{T}$;

$p=$ probability representing the occurrence of each draw $\mathrm{C}$.

With respect to the utility function, the power utility function was selected, implying CRRA. The function considers that uncertain cash flows determined for the whole-farm strategy are in total large relative to farmers' wealth. As the model takes a long term perspective, wealth $\mathrm{w}$ is a product of annual income $\mathrm{y}$ and the capitalization factor $\mathrm{k}$, therefore the same $r$ may be applied for wealth and income $\left(\mathrm{r}_{\mathrm{r}}(\mathrm{w})=\mathrm{r}_{\mathrm{r}}(\mathrm{ky})=\mathrm{r}_{\mathrm{r}}\right.$ (y)) (Hardaker et al., 2004:112-113). After obtaining the $E U Y_{T}$, the inverse of the expected utility results in the associated certainty equivalent $\left(C E_{T}\right)$. Finally all certainty equivalents are summed up to a total $\mathrm{CE}$, calculated for the whole production period. The UEP model was solved with GAMS/CONOPT3 (General Algebraic Modeling System (GAMS) 2.0.33.5, GAMS Development Corporation, Washington DC, USA).

All variables included in the cash flow calculation $C F_{T C}$ are variety specific and were calculated by considering six different varieties $V$ (Equation 4).

$$
\begin{aligned}
C F_{T C}= & {\left[\left(\sum_{v=1}^{n} \text { oprev }_{T C V}+\text { nonoprev }_{T C V}-\text { cdet }_{T C V}-\text { cvar }_{T C V}-\text { cadd }_{T C V}-\text { cstorage }_{T C V}\right)-\right.} \\
& \text { cdirectsale } \left._{T C}\right] \times(1+i)^{-t}
\end{aligned}
$$

Where

$C F_{T C}=$ discounted cash flow per production year;

oprev $_{T C V}=$ operating revenue as product of apples sold and associated prices;

nonoprev $_{T C V}=$ non-operating revenue including indemnity payments as well as subsidies;

$c d e t_{T C V}=$ deterministic costs (i.e. costs for fertilizer, plant protection, insurance, material for hail net installation);

$\mathrm{cvar}_{T C V}=$ variable costs (variable wage and machinery costs for sorting and harvesting)

${ }_{c a d d} d_{T C V}=$ further costs (fixed wage and machinery costs referring to frost irrigation activities and harvesting); cstorage $_{T C V}=$ storage costs - referring to qualities extra one and two;

cdirectsale $_{T C}=$ costs for direct sale to consumers, calculated per year over all varieties and apples sold.

As higher discounting leads to a reduction of the cash flow variance, the cash flow calculation was carried out for discount rates $i=0.04,0.06$ and 0.08 . For the north, a planted area of 20 ha per farm is assumed and for the south $15 \mathrm{ha}$. As establishing costs of $26,187 € /$ ha north and $26,715 € /$ ha in the south are considered to be equal for each apple variety, these are excluded from the analysis. Furthermore, variations in the cultivation 
plan, as tree removal and re-cultivation are not included. An overview of the most relevant parameters is given in Table 1.

Variables which are relevant for the calculation of the discounted cash flows are area of planted apple, amount of processing fruits, amount of stored fruits, storage costs, and the sale specifications. Here, the common distribution channels for apple in Germany, i.e. the wholesale market or the direct sale to consumers are considered.

The availability of land is set to a fixed value of 15 ha in the south and 20 ha in the north. Furthermore, pollination requirements are considered. For large-scale production, triploid and diploid varieties have to be established in a mixed orchard planting (Way, 1995:6) therefore a minimum of 7\% of compatible varieties is required. As $43 \%$ of the apple growers sell a share of apples direct to consumers, a minimum restriction of 1 ha of each variety is set to ensure a diversified product portfolio.

The programming tool further considers different production options per variety, therefore the amounts of stored fruits as well as those of processing fruits have to be aggregated in order to represent the total amount of apple per variety. Processing fruits are only assumed to be sold at the wholesale market but not direct to consumers. Storage costs are calculated for higher-quality apples, which are generally stored in controlled atmosphere, or at least in cold storage for a short-term warehousing, assuming average storage costs of $7.66 €$ per dt (KTBL, 2010). According to the numbers stated by apple growers, an average loss of $5 \%$ is assumed during storage.

Values obtained from the survey suggest that direct sales activities in average amounts to $13 \%$ for high quality apple in the north and $17 \%$ in the south. Therefore, these values are used as maximum restrictions for direct sales activities in the model. The model structure is shown in Figure 1.

Eighteen different activities per region are defined in the UEP-Model. When insuring apple against hail, insurers generally require that the complete pome fruit area is covered. As a consequence, two separate scenarios per region were calculated - with and without insurance schemes. Insurance premiums (IP), applicable to all varieties per region, were implemented as fair premiums, i.e. that calculated indemnity payments equals insurance costs. In order to consider transaction costs, additional costs of $30 \%$ of the fair premium were added.

Indemnity payments regarding hail damages are calculated as total loss ratio from hail (TLRH) and represent both, quantitative yield losses $(Q Y L)$ as well as quality-related yield losses $(Q R Y L)$ due to hail (Equation 5). As the juvenile phase of the orchard, i.e. the initial three years after planting, is considered as a deterministic component, the average standard yield was calculated for the time period of years four to twenty.

Table 1. Overview of relevant parameters serving as input data for cash flow calculation.

\begin{tabular}{lll}
\hline Parameter & Unit & Source \\
\hline Yield & $\mathrm{dt} / \mathrm{ha}$ & $\begin{array}{l}\text { Yield estimates of apple growers combined with historical data, } \\
\text { stochastic @ } \text { risk model }\end{array}$ \\
Prices & $€ / \mathrm{dt}$ & $\begin{array}{l}\text { Price estimates of apple growers combined with historical data, } \\
\text { stochastic @ } \text { risk model }\end{array}$ \\
Costs & $€ / \mathrm{ha}$ & KTBL, 2010, stochastic @ risk model \\
Non-operating revenue & $€ / \mathrm{ha}$ & Stochastic @ risk model \\
Discount rate & $\%$ & $\mathrm{i}=0.04,0.06,0.08$ \\
Relative risk aversion coefficients $(r)$ & - & $0,0.2,0.4,0.6,0.8,1.2,1.4,1.6,1.8,2$ \\
\hline
\end{tabular}




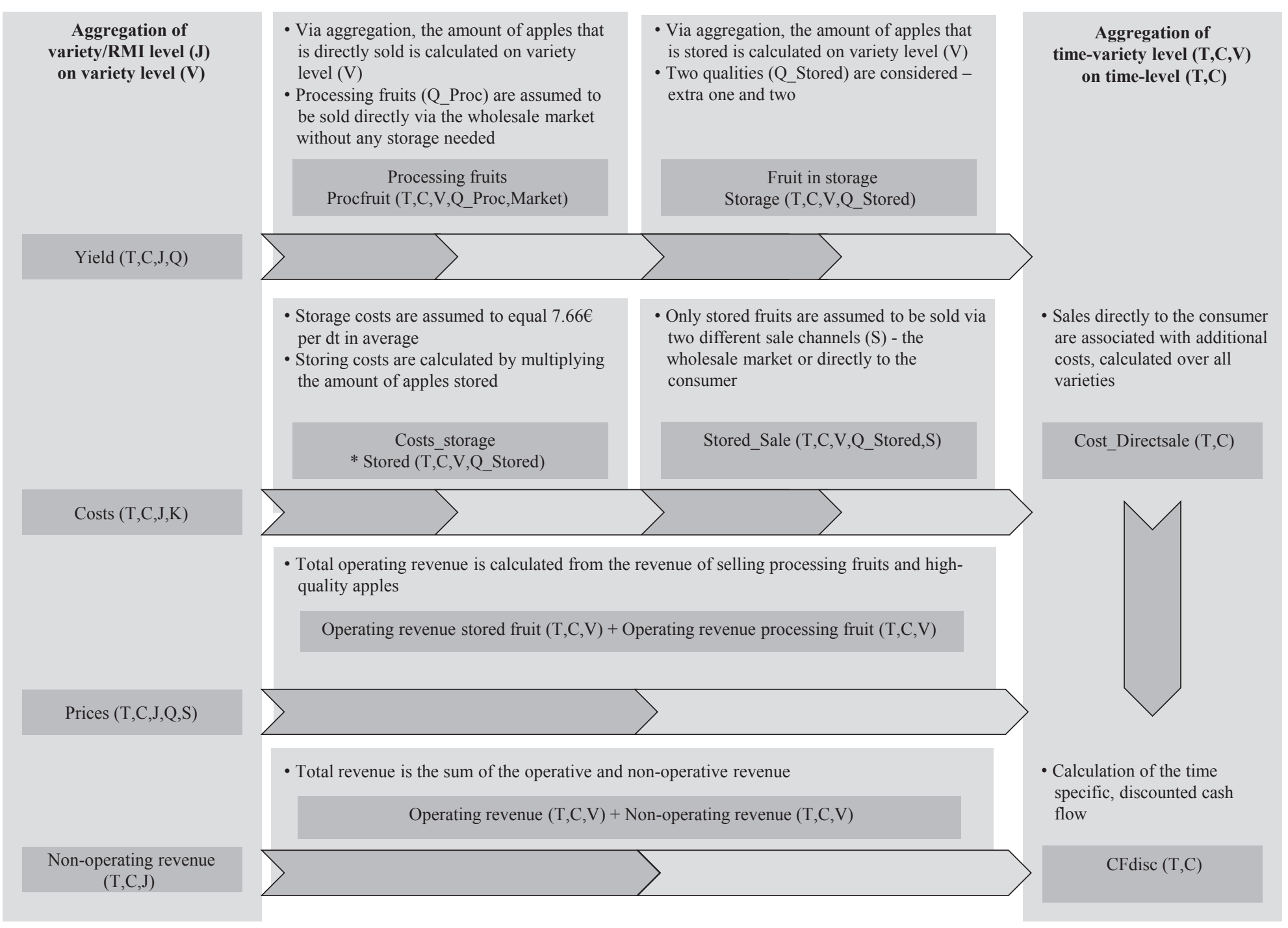

Figure 1. Model structure. RMI = risk management instruments; $\mathrm{T}=$ years 0-20; 100 drawings $\mathrm{C}$, J, variety plus RMI; V = variety independent of RMI; Q = quality, Q_stored = high quality apples which are stored; Q_Proc = apples serving as processing fruits; $\mathrm{S}=$ sale channel; Market = sale via wholesale market; $\mathrm{K}=$ costs (incorporates direct, additive and variable costs). 


$$
T L R H_{a}=\left[\left(Q Y L_{a}+Q R Y L_{a}\right) \times\left[1 / 16 \times\left(\sum_{a=4}^{20} Y_{a} \times\left(1-F Y R_{a}\right)\right)\right]^{-1}\right] \times 100
$$

Where

$Y_{a}=$ yield for each year 4-20;

$F Y R_{a}=$ frost-related yield loss, which usually occur before damages due to hail;

$Q Y L=$ quantitative yield losses;

$Q R Y L=$ quality-related yield losses.

Similarly, parameters regarding frost insurance were calculated. However, for frost only yield related damages are considered and as current insurance schemes for combined hail-frost insurances suggest, no deductibles for frost are calculated. For indemnity calculation, the sum insured equals the calculated sum insured for hail and indemnities for frost damages are subtracted from the total sum insured before hail indemnities are calculated (for a more detailed description of the calculations, please refer to (Röhrig et al., 2018).

For the north the activities included in the model can be characterized as follows.

1. Variety Boskoop with 3,300 trees per hectare and IFP.

2. Variety Braeburn with 3,300 trees per hectare and IFP.

3. Variety Elstar with 3,300 trees per hectare and IFP.

4. Variety Holsteiner Cox with 3,300 trees per hectare and IFP.

5. Variety Jonagored with 3,300 trees per hectare and IFP.

6. Variety Red Prince with 3,300 trees per hectare and IFP.

Activities 1-6 are further implemented in combination with subsidized HI (10\% of the sum ensured equals the insurance premium) (activities 7-12) and subsidized FI sub \& HI sub (7\% premium for frost and 10\% premium for hail), which provides an alternative to IFP (activities 13-18).

For the south following sets are considered.

1. Variety Boskoop with 3,500 trees per hectare and HN (grey).

2. Variety Braeburn with 3,500 trees per hectare and $\mathrm{HN}$ (grey).

3. Variety Elstar with 3,500 trees per hectare and $\mathrm{HN}$ (grey).

4. Variety Gala with 3,500 trees per hectare and HN (grey).

5. Variety Jonagold with 3,500 trees per hectare and HN (grey).

6. Variety Jonagored with 3,500 trees per hectare and HN (grey).

Similarly to the north the scenarios of the south were also calculated for a subsidized HI (21\% insurance premium) and subsidized FI sub \& HI sub (2\% premium for frost and $21 \%$ premium for hail). As subsidies cover up to $50 \%$ of installation of $\mathrm{HN}$ and insurance premium costs, following assumptions were made: in the south the material for hail nets and insurance premiums are subsidized by $50 \%$, up to an absolute ceiling of $12,000 € /$ ha for hail nets. In the north, the calculation is based on a multiplication of the sum insured with a distribution factor. This distribution factor represents $1 \%$ of the marketed production and claim settlements, divided by the sum insured over all enterprises. Subsidies may not exceed the costs of the insurance premium and the sum insured is limited to $20,000 € /$ ha. It is assumed that the installation of frost irrigation systems is not eligible for subsidies.

Unsubsidized insurances are not considered in this work as subsidized schemes are available in both regions. Furthermore, the work of Röhrig et al. (2018) has shown that unsubsidized hail insurance in combination with frost irrigation in the north, provides only slightly higher benefits than frost irrigation alone, given a high level of risk aversion. In the south unsubsidized hail insurance generally results in lower utilities when compared to hail nets (Röhrig et al., 2018), representing only an alternative if hail nets are not permitted. Thus, we expect unsubsidized insurance solutions not to be part of an optimal farm plan when subsidized ones are available. A separate frost insurance was not integrated either, as even the combination of a multiperil frost-hail insurance has not achieved the utility of frost irrigation as single risk management tool, 
considering the production of high-yielding varieties on an area of one hectare (Röhrig et al., 2018). In addition, comparable, multi-peril insurance schemes for securing against frost and hail damages are available for instance in Austria, where insurances refer to the same sum insured for hail and frost damages.

Labor and cash resources are not limited in the model because liquidity can be managed by formal credits at reasonable costs and fruit farms generally are creditworthy. Besides this assumption, apple growers have access to labor and thus the question of manpower during work peaks is not addressed (cf. Dorward, 1999; Janssen and van Ittersum, 2007).

\section{Generating input data for utility efficient risk programming}

The next section provides details on weather-related risks and region specific risk management strategies. In the following two sections, the elicitation of risk perception as well as the implementation of stochastic dependencies and stochastic simulation of probability distributions is described, from which input data for the model were generated.

Apple production in Germany mainly concentrates on two production regions, namely "Altes Land", which is situated in the northern part, near the river mouth of the Elbe and the area of Lake Constance, located 900 $\mathrm{km}$ towards south, close to the Alps. Climatic conditions promote the occurrence of different risks causing yield and quality reductions of apple. Late frosts frequently cause yield loss in the north, but also damages due to hail. Considering the past ten production years, data of the survey show that $63.2 \%$ of the apple growers in the south suffered from yield losses due to hail and $48.5 \%$ in the north. For late frosts $54.4 \%$ of the southern apple growers reported associated yield losses and $66.7 \%$ of the northern farmers. Besides these major weather-related risks, sunburn may cause quality reductions. In this context, HN are not suited for the production of high quality apple in the north, as light absorption reduces the fruit coloring. Thus, apple growers in the north can only choose hail insurance to hedge against hail-related risks. In contrast, IFP allows mitigating late frosts as well as sunburn, which makes IFP a mandatory instrument in the north. In the south hail is seen as a predominant source of risk and $\mathrm{HN}$ are mainly installed for securing against severe yield and quality reductions. Dark-colored HN protect apples from sunburn due to UV absorption as a side-effect.

For assessing these region specific sources of risk, farmers' risk attitude and perceptions were elicited in winter 2013/2014. Apple growers were first contacted by local extension and research stations, which sent invitation letters or a call for participation, disclosed in the newsletter of the producer organizations. Finally, surveys with 66 apple growers in the north and 68 in the south were conducted via face-to-face interviews lasting for about two hours.

Capturing future uncertainty in apple production requires an ample set of data on parameters like yield, price, quality and losses. For eliciting farmers' perceptions of yield risk, the estimation of probabilities based on the experience technique was applied, which only requires solely the minimum, maximum and modal value of the relevant parameter (Hoag, 2010:212-213). However, the pretest revealed that farmers were uncomfortable applying this technique for the areas of specific yield losses and apple prices. Thus, according to the approach of Menapace et al. (2013), these parameters were determined by applying a modified fixed value method based on the strength of conviction technique, which means that farmers are not asked to state probabilities, directly (Senkondo, 2000:31-32). Before apple growers were asked to make their estimates for future events, they were requested to recall the frequency of different events, occurring during the past 10 years, in order to obtain less biased input data. Afterwards, apple growers' were asked to state their expectations for the upcoming production years by allocating ten years to intervals, which contain values that represented losses and prices. Finally, these absolute frequencies were converted into relative ones (cf. Röhrig et al., 2018). An example is given in Figure 2.

Apple variety specific distributions of quality, weather related losses and prices were constructed, using the midpoints of the given intervals and the calculated, relative frequencies. A correlation structure, considering 


\begin{tabular}{|c|c|c|c|c|c|}
\hline \multicolumn{3}{|c|}{$\begin{array}{l}\text { Your expectation for the next ten } \\
\text { years: how often will frost lead to the } \\
\text { following losses (\%). Please allocate } \\
\text { ten years to the given intervals: }\end{array}$} & \multicolumn{3}{|c|}{$\begin{array}{l}\text { If your expectation is based on the } \\
\text { existence of frost irrigation, which } \\
\text { losses would you expect under the } \\
\text { absence of frost irrigation? }\end{array}$} \\
\hline $\begin{array}{l}\text { Loss due to } \\
\text { frost (\%) }\end{array}$ & $\begin{array}{c}\text { Absolute } \\
\text { (estimation) }\end{array}$ & $\begin{array}{l}\text { Relative } \\
\text { (calculated) }\end{array}$ & $\begin{array}{c}\text { Loss due to } \\
\text { frost }(\%)\end{array}$ & $\begin{array}{c}\text { Absolute } \\
\text { (estimation) }\end{array}$ & $\begin{array}{c}\text { Relative } \\
\text { (calculated) }\end{array}$ \\
\hline $0 \%$ & 9 & 0.9 & $0 \%$ & 8 & 0.8 \\
\hline $1-4 \%$ & & & $1-4 \%$ & & \\
\hline $5-9 \%$ & & & $5-9 \%$ & & \\
\hline $10-19 \%$ & & & $10-19 \%$ & & \\
\hline $20-29 \%$ & 1 & 0.1 & $20-29 \%$ & & \\
\hline $30-39 \%$ & & & $30-39 \%$ & 1 & 0.1 \\
\hline $40-49 \%$ & & & $40-49 \%$ & & \\
\hline $50-59 \%$ & & & $50-59 \%$ & 1 & 0.1 \\
\hline $60-69 \%$ & & & $60-69 \%$ & & \\
\hline $70-79 \%$ & & & $70-79 \%$ & & \\
\hline $80-89 \%$ & & & $80-89 \%$ & & \\
\hline $90-100 \%$ & & & $90-100 \%$ & & \\
\hline
\end{tabular}

Figure 2. Application of the modified fixed value method related to the survey design.

intra- and intertemporal dependencies of yield and prices related to different varieties, has been implemented via the historical data approach, which combines elicited yield and price distributions with historical data (Hardaker et al., 2004:80-82). Historical price data were used from ZMP and AMI (ZMP, 1998:77-79, 2002:68-69, 2006:25-27) and AMI (2013:74-76)). Furthermore, price data was corrected for inflation, applying the consumer price indices of the year 2010, provided by the Federal Statistical Office (2014). Yield data were obtained from the statistical office of the federal state (Landesamt für Statistik Niedersachsen, 2017). Afterwards, MS Excel (version 14.0.7208 Microsoft Corporation, Redmond, WA, USA) allows deriving distributions of parameters for cash flow calculations by applying the Palisade add-in @ Risk for Latin Hypercube simulation (@Risk6.0 Industrial Edition, Palisade Corporation, Ithaca, NY, USA).

\section{Results and discussion}

Apple growers have to face weather-related risks throughout their daily business. Thus, a whole-farm model based on UEP was developed in order to assess the effects of different RMI. The perceived yield losses related to frost in the north and hail in the south with and without on-farm risk management tools are displayed in Figures 3 and 4.

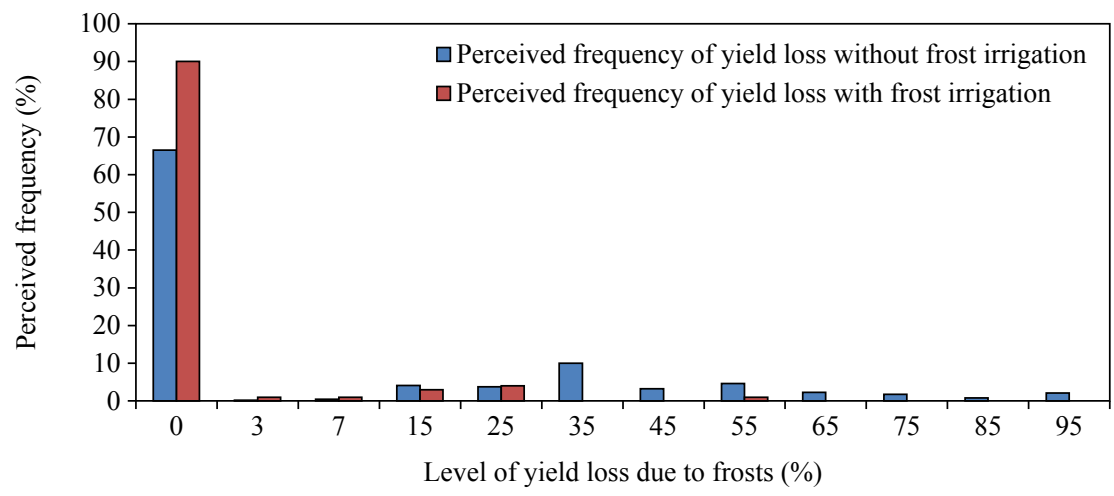

Figure 3. Perceived yield loss due to frosts (north). 


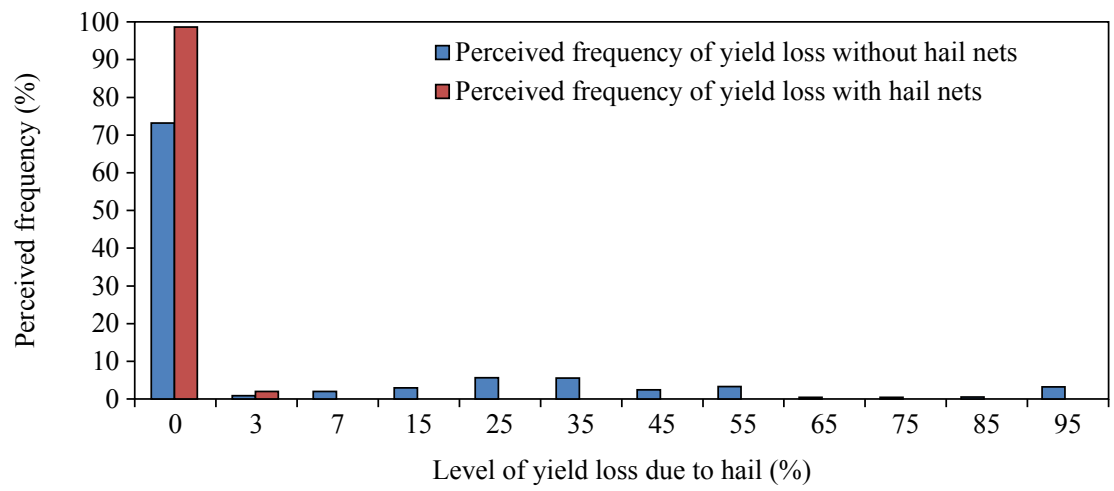

Figure 4. Perceived yield loss due to hail (south).

Table 2 provides an example of the results of the simulation model for a Red Prince scenario with frost irrigation and subsidized hail insurance for the north. It shows the calculated mean, the standard deviation (Stdv), the coefficient of variance $(\mathrm{CV})$, as well as the $5 \%\left(\mathrm{Q}_{0.05}\right)$ and $95 \%\left(\mathrm{Q}_{0.95}\right)$ percentiles and the associated Minimum (Min) and Maximum (Max) in decitonnes (dt) or on hectare-level (ha). In case of a subsidized hail insurance, the sum insured may not exceed 20,000€/ha in the north, otherwise subsidies are

Table 2. Variety specific data for Red Prince IFP \& HI sub obtained for apple production in the north. ${ }^{1}$

\begin{tabular}{|c|c|c|c|c|c|c|c|c|}
\hline & & Mean & Stdev & $\mathrm{CV}$ & $\mathbf{Q}_{0.05}$ & $Q_{0.95}$ & Min & $\operatorname{Max}$ \\
\hline Deterministic costs & $€ /$ ha & $4,603.92$ & 0.00 & 0.00 & $4,603.92$ & $4,603.92$ & $4,603.92$ & $4,603.92$ \\
\hline Variable costs & $€ /$ ha & $4,494.39$ & 735.97 & 0.16 & $2,951.56$ & $5,466.56$ & $1,167.38$ & $5,466.56$ \\
\hline Fixed cost & $€ /$ ha & $3,965.53$ & 500.01 & 0.13 & $3,014.11$ & $4,696.66$ & $1,938.45$ & $4,925.67$ \\
\hline Total yield & $\mathrm{dt} / \mathrm{ha}$ & 575.61 & 123.28 & 0.21 & 317.18 & 738.45 & 18.32 & 738.45 \\
\hline Classes extra and one & $\mathrm{dt} / \mathrm{ha}$ & 442.92 & 144.87 & 0.33 & 171.57 & 651.22 & 3.14 & 719.99 \\
\hline Class two & $\mathrm{dt} / \mathrm{ha}$ & 26.50 & 35.24 & 1.33 & 0.00 & 101.89 & 0.00 & 165.60 \\
\hline Processing fruit & $\mathrm{dt} / \mathrm{ha}$ & 106.19 & 112.96 & 1.06 & 13.27 & 324.33 & 0.58 & 705.85 \\
\hline $\begin{array}{l}\text { Market price processing fruit } \\
\text { (current year) }\end{array}$ & $€ / \mathrm{dt}$ & 11.38 & 3.92 & 0.34 & 5.24 & 19.35 & 5.24 & 19.35 \\
\hline $\begin{array}{l}\text { Market price classes extra and } \\
\text { one (stored) }\end{array}$ & $€ / \mathrm{dt}$ & 48.02 & 8.46 & 0.18 & 33.79 & 61.20 & 33.79 & 61.20 \\
\hline Market price class two (stored) & $€ / \mathrm{dt}$ & 31.98 & 9.84 & 0.31 & 17.30 & 53.28 & 17.30 & 53.28 \\
\hline $\begin{array}{l}\text { Farmer to consumer price } \\
\text { classes extra and one (stored) }\end{array}$ & $€ / \mathrm{dt}$ & 185.52 & 29.37 & 0.16 & 136.10 & 231.28 & 136.10 & 231.28 \\
\hline $\begin{array}{l}\text { Farmer to consumer price class } \\
\text { two (stored) }\end{array}$ & $€ / \mathrm{dt}$ & 86.81 & 22.51 & 0.26 & 53.21 & 135.54 & 53.21 & 135.54 \\
\hline Sum insured & $€ /$ ha & $20,000.00$ & 0.00 & 0.00 & $20,000.00$ & $20,000.00$ & $20,000.00$ & $20,000.00$ \\
\hline Indemnity payments hail & $€ /$ ha & $1,980.44$ & $3,401.74$ & 1.72 & 0.00 & $9,707.88$ & 0.00 & $20,000.00$ \\
\hline Insurance premium hail & $€ /$ ha & $2,000.00$ & 0.00 & 0.00 & $2,000.00$ & $2,000.00$ & $2,000.00$ & $2,000.00$ \\
\hline Indemnity payments frosts & $€ /$ ha & 0.00 & 0.00 & 0.00 & 0.00 & 0.00 & 0.00 & 0.00 \\
\hline Insurance premium frosts & $€ /$ ha & 0.00 & 0.00 & 0.00 & 0.00 & 0.00 & 0.00 & 0.00 \\
\hline Hail insurance costs & $€ /$ ha & $2,600.00$ & 0.00 & 0.00 & $2,600.00$ & $2,600.00$ & $2,600.00$ & $2,600.00$ \\
\hline Frost insurance costs $€ /$ ha) & $€ /$ ha & 0.00 & 0.00 & 0.00 & 0.00 & 0.00 & 0.00 & 0.00 \\
\hline Subsidies hail insurance & $€ /$ ha & 848.71 & 0.00 & 0.00 & 848.71 & 848.71 & 848.71 & 848.71 \\
\hline Subsidies frost insurance & $€ /$ ha & 0.00 & 0.00 & 0.00 & 0.00 & 0.00 & 0.00 & 0.00 \\
\hline
\end{tabular}


not paid out. For Red Prince, simulated with 3,300 trees per hectare, the value of 20,000 €/ha is restrictive and represents the maximum.

The variety specific portfolio for apple production in the north with IFP as single RMI is displayed in Figure 5. As can be observed, the variety Red Prince covers the largest portion of the entire portfolio. With respect to $r$ near zero, the other varieties are included with solely at the minimum level of 1 ha required by the market portfolio restriction, whereas Red Prince should be produced on an area of 15 ha. At a risk aversion coefficient $r=0.6$, diversification starts with increasing shares of Braeburn and Holsteiner Cox (Figure 5). In this context, the varieties Braeburn and Holsteiner Cox substitute Red Prince, as they show the lowest coefficient of variation (CV) and allow for the highest mean NPV after Red Prince (Table 3). Furthermore, diversification declines when high levels of risk aversion are reached. Based on its mean NPV, Jonagored would be the next best option, but the CV of Jonagored is higher than those of the other favored varieties, which explains the stagnation of diversification for higher degrees of risk aversion (Figure 5).

A comparison of insurance-based risk management strategies, applied as a combination of IFP and subsidized hail insurance (IFP \& HI sub) as well as a combined frost-hail insurance (FI sub \& HI sub) is given in Figure 6 . The question arises, whether a permanent payment against frost damage is worthwhile if the availability of goods is endangered due to the absence of frost irrigation. Obviously, the appropriateness of FI sub \& HI sub increases with the individual's degree of risk aversion, but a combination of IFP \& HI sub still remains the dominant risk management strategy. Even the proportion of FI sub \& HI sub is smaller than those of IFP \& HI sub, this RMI seems to be the appropriate tool for diversification, given that revenues are not significantly reduced due to the absence of IFP. In the model this is specifically the case for Elstar and Boskoop, both varieties show an increased tendency for alternate bearing and thus lower average yield levels (e.g. Winter, 2002:100-101). For these varieties the revenue loss under abandonment of IFP is smaller than for the high yielding varieties like Red Prince and Holsteiner Cox, which are also attaining high prices. In this context, Braeburn shows a moderate yield level but relatively high prices, whereas Jonagored is a high yielding variety but prices, especially those for the class extra and one, are below those of Red Prince and Holsteiner Cox. This explains why Braeburn and Jonagored with FI sub \& HI sub as RMI become part of the portfolio when higher $r$ are considered. These findings support the idea to provide a subsidized FI sub \& HI sub in Germany as an appropriate RMI. Especially for low yielding varieties or those sold at lower prices, the absence of IFP can be compensated through indemnity and subsidy payments of the FI sub \& HI sub. This option might be interesting, in particular for apple growers who do not have access to water springs like the river Elbe to obtain water for IFP.

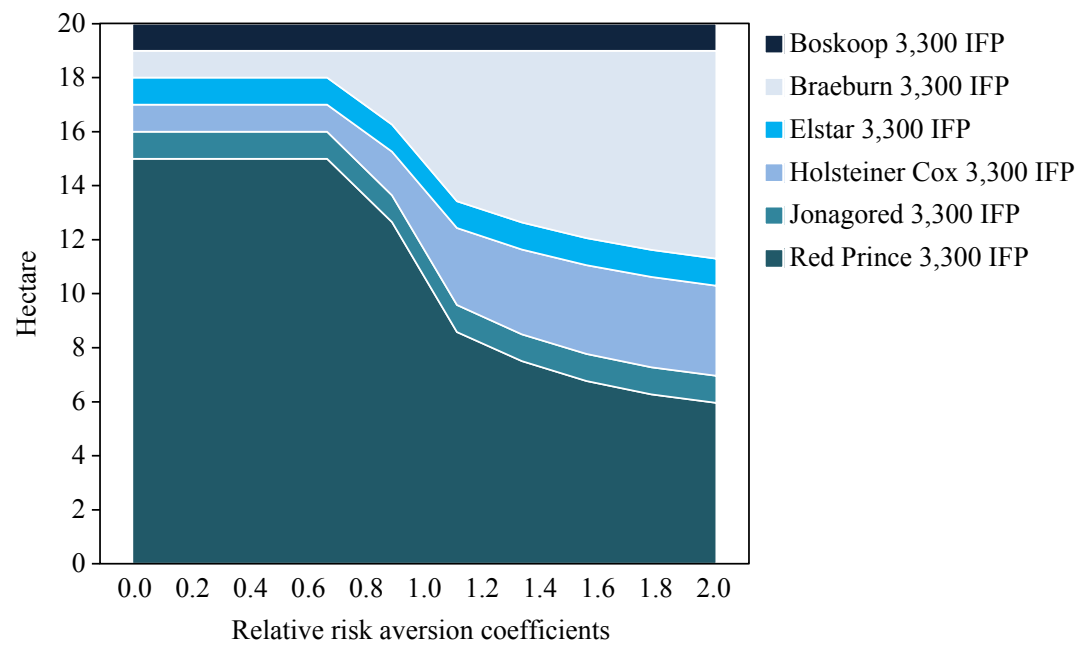

Figure 5. North - Results for irrigation for frost protection (IFP) as risk management instruments and a $4 \%$ discount rate as discounting factor. 
Table 3. Variety specific data - net present value (NPV) ${ }^{1}$ per ha ( $4 \%$ discount rate as discounting factor) for apple production in the north, obtained with linear programming (Solver CPLEX in GAMS). ${ }^{2}$

\begin{tabular}{lrll}
\hline & NPV Mean & NPV Stdev & CV \\
\hline Boskoop IFP & 39 & 52 & 1.32 \\
Braeburn IFP & 113 & 75 & 0.67 \\
Elstar IFP & 75 & 60 & 0.80 \\
Holsteiner Cox IFP & 115 & 73 & 0.64 \\
Jonagored IFP & 87 & 94 & 1.08 \\
Red Prince IFP & 120 & 87 & 0.73 \\
Boskoop IFP \& HI sub & 39 & 46 & 1.17 \\
Braeburn IFP \& HI sub & 114 & 54 & 0.48 \\
Elstar IFP \& HI sub & 76 & 51 & 0.68 \\
Holsteiner Cox IFP \& HI sub & 114 & 55 & 0.48 \\
Jonagored IFP \& HI sub & 88 & 88 & 1.00 \\
Red Prince IFP \& HI sub & 121 & 74 & 0.61 \\
Boskoop FI sub \& HI sub & 42 & 44 & 1.04 \\
Braeburn FI sub \& HI sub & 110 & 51 & 0.46 \\
Elstar FI sub \& HI sub & 74 & 55 & 0.74 \\
Holsteiner Cox FI sub \& HI sub & 109 & 53 & 0.49 \\
Jonagored FI sub \& HI sub & 84 & 84 & 1.00 \\
Red Prince FI sub \& HI sub & 112 & 70 & 0.62 \\
\hline 1
\end{tabular}

${ }^{1} \mathrm{NPV}$ in $1000 €$.

${ }^{2}$ IFP = irrigation for frost protection; FI sub = subsidized frost insurance; HI sub = subsidized hail insurance.

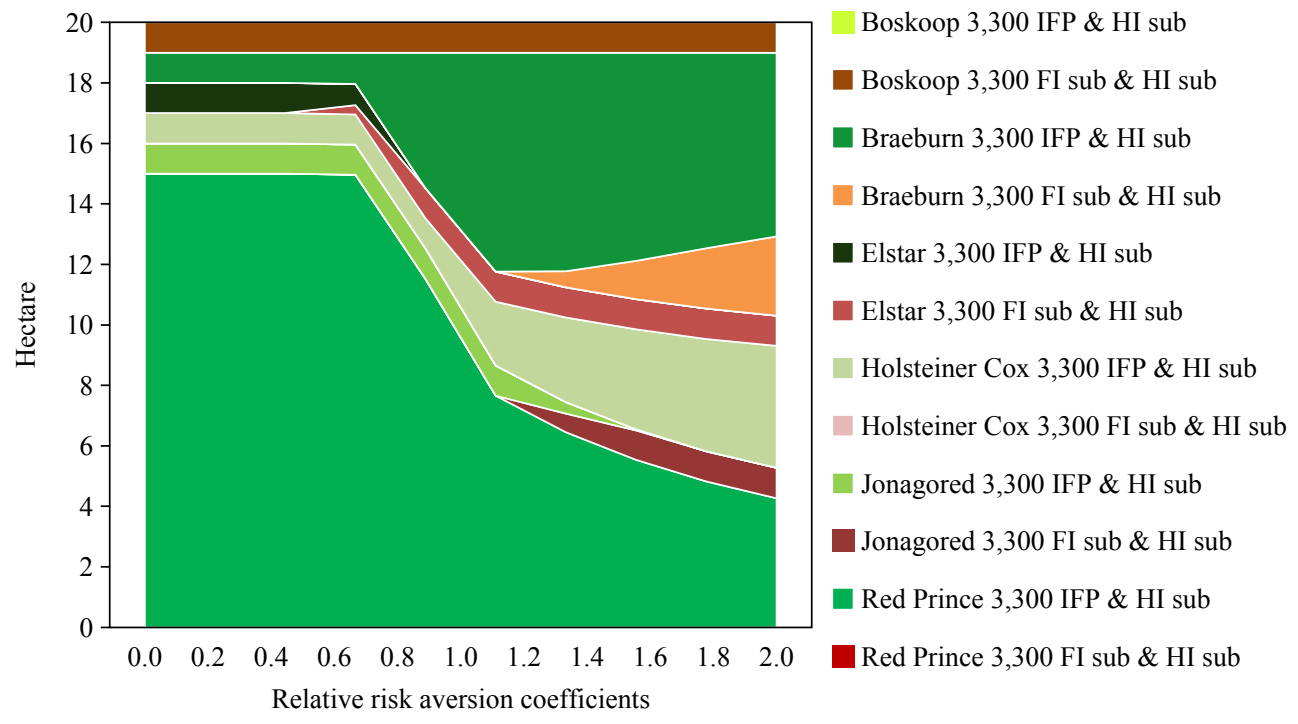

Figure 6. North - Results for FI sub \& HI sub as well as IFP \& HI sub as RMI and a 4\% discount rate as discounting factor.

As increasing discounting rates lead to the reduction of variance (Lien et al., 2007), additional simulations were performed for discount rates of $6 \%$ and $8 \%$ in order to capture the effects on the optimal whole farm plan. By increasing discount rates, diversification effects occur at higher levels of risk aversion. For IFP as single RMI, the substitution of Red Prince begins at higher $r$, which holds also for the insurance scenario (cf. Figures 5, 6, 7, 8). However, the influence on the portfolio's composition is negligible. As observed for 


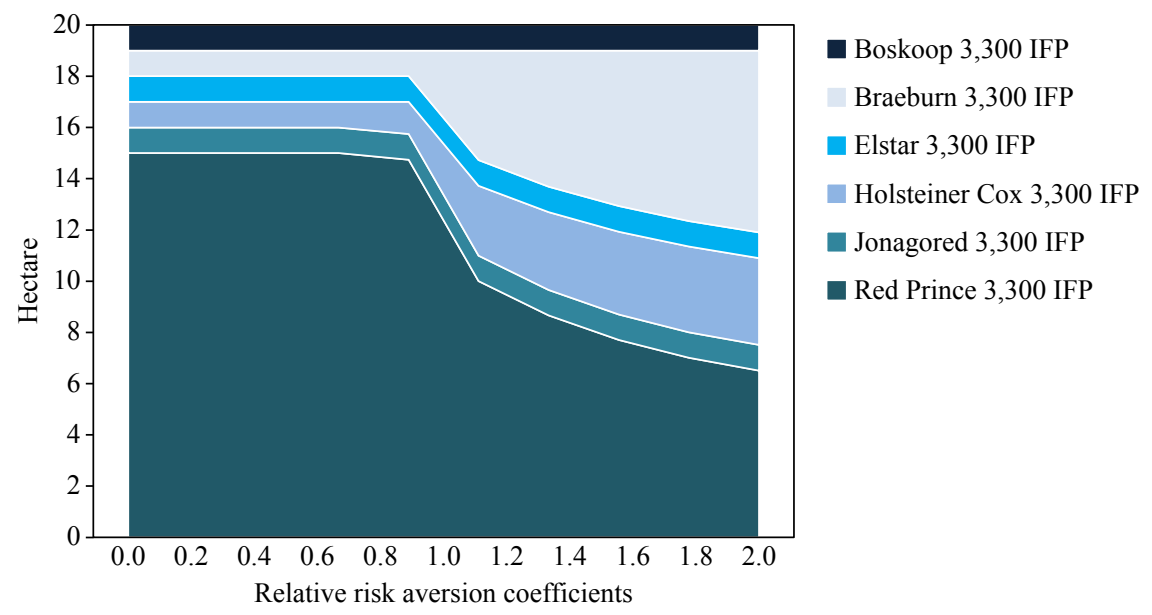

Figure 7. North - Results for IFP as RMI and an $8 \%$ discount rate as discounting factor.

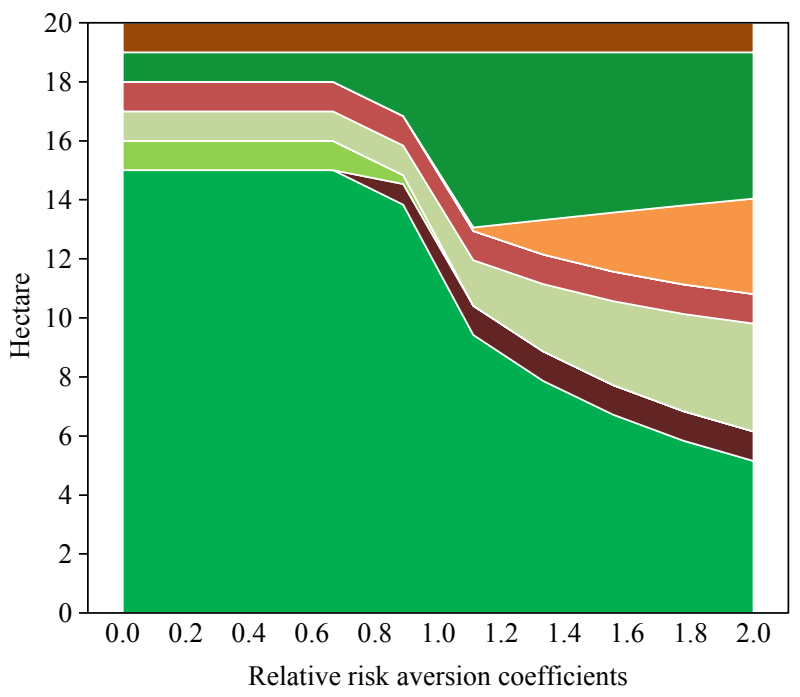

\footnotetext{
Boskoop 3,300 IFP \& HI sub

Boskoop 3,300 FI sub \& HI sub

Braeburn 3,300 IFP \& HI sub

Braeburn 3,300 FI sub \& HI sub

Elstar 3,300 IFP \& HI sub

Elstar 3,300 FI sub \& HI sub

Holsteiner Cox 3,300 IFP \& HI sub

Holsteiner Cox 3,300 FI sub \& HI sub

Jonagored 3,300 IFP \& HI sub

Jonagored 3,300 FI sub \& HI sub

Red Prince 3,300 IFP \& HI sub
}

Red Prince 3,300 FI sub \& HI sub

Figure 8. North - Results for FI sub \& HI sub as well as IFP \& HI sub as RMI and an $8 \%$ discount rate as discounting factor.

a discount rate of 4\%, the differentiation of the portfolio declines for high $r$. Regarding the highest $r$ applied, all scenarios equally show that Red Prince is included with only about one third of the area, compared to the area which should be cultivated by a risk neutral apple grower, characterized by $r$ of 0 .

The CEs of the north concerning the basic scenario with frost irrigation and the insurance scenario are given in Figure 9. As theoretically expected, the CEs are decreasing with increasing $r$ due to the enhanced concavity of the associated utility functions. Furthermore, higher discounting rates generally lead to lower CEs. As can be seen in Figure 9, the CEs related to the insurance-based portfolio, indicated by the dashed lines, descent not as strong as those of the IFP scenario. This implies that a combination of traditional IFP with insurance solutions generally results in higher expected utilities. Since the CEs of the whole planning period are comparable to NPVs, annuities, directly derived from the CEs, can be seen as the expected cash flow per year. The analysis further indicates that insurance solutions may lead to higher annuities in the north, even if only slight risk aversion is assumed (Figure 10). Thus, indemnity payments and subsidies offset additional costs of insurance participation. 


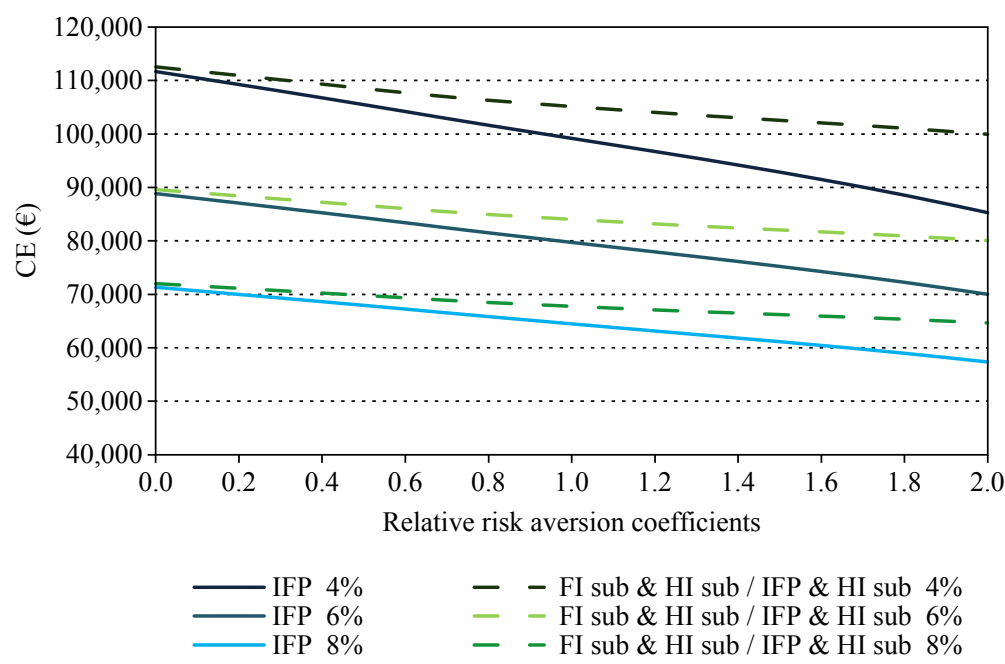

Figure 9. North - Certainty equivalents (CEs) of the portfolios IFP and FI sub \& HI sub/IFP \& HI sub as RMI.

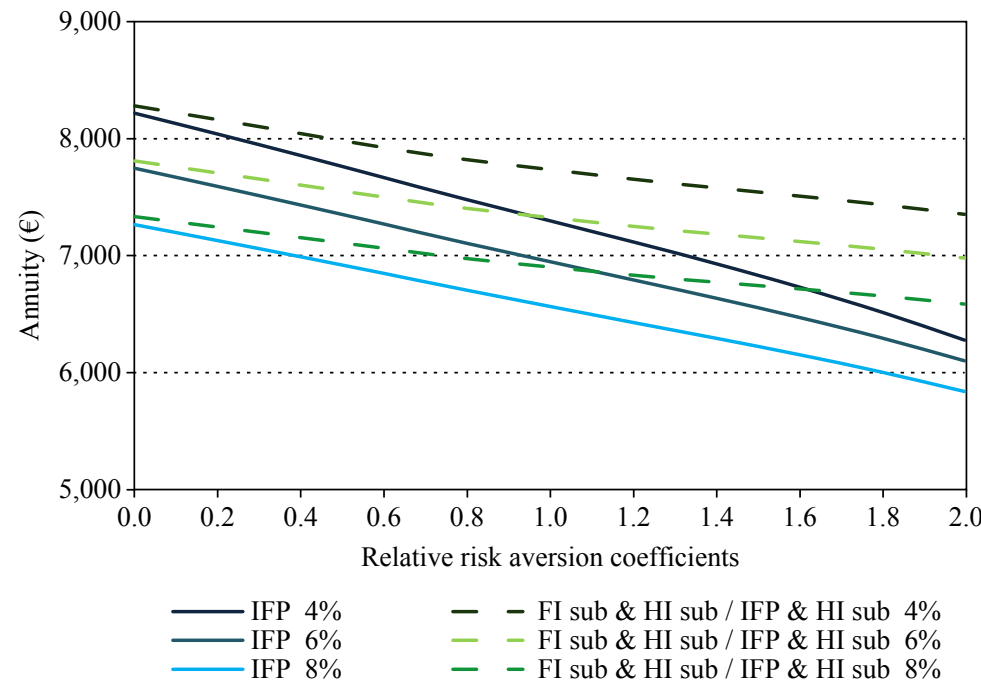

Figure 10. North - Annuities of the portfolios IFP and FI sub \& HI sub/IFP \& HI sub as RMI.

Similar results were obtained for apple production in the south, usually realized with $\mathrm{HN}$ as risk management strategy, revealing a non-relevant effect of the discounting rate. Contrary to the result obtained for the north, higher risk aversion nearly has no impact on the portfolio composition in the south and only minor diversification activities are observed (Figure 11). Braeburn represents the most favorable variety with an area of 10 ha for all $r$ with only slight differences. These observations made for the south are in line with the results obtained by Lien and Hardaker (2001), who found nearly no changes in optimal farm plans when applying relative risk aversion $r$ in the range of 0.5 to 4 . As indicated in Table 4 , this variety provides the lowest CV as well as the highest mean NPV, which explains its dominance within the calculated portfolio. Nevertheless, under consideration of a high risk aversion of $r=1.6$ and above, Braeburn is substituted by Jonagold, which is characterized by a high NPV but a moderate CV (Table 4). Portfolios obtained for insurance solutions as an alternative for $\mathrm{HN}$ in the south revealing that FI sub \& HI sub is the preferred insurance concept (Figure 12).

Figure 13 depicts the related CEs obtained for the south. Generally the CEs and annuities of the south are only half the size of those calculated for the north. The reason for this deviation can be found when comparing 


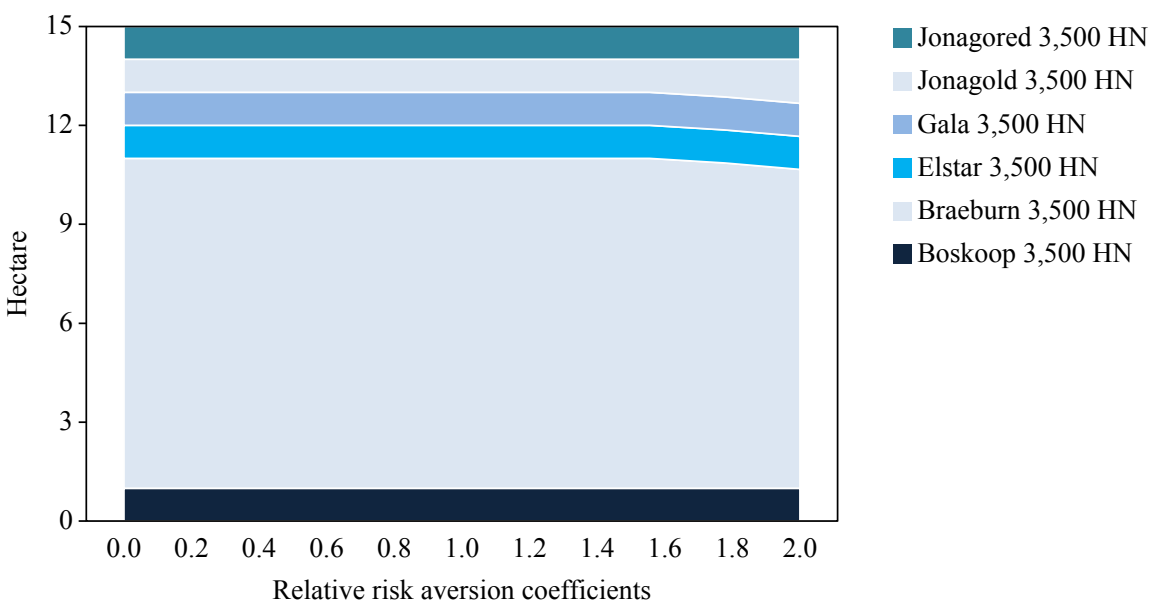

Figure 11. South - Results for $\mathrm{HN}$ as RMI and a 4\% discount rate as discounting factor.

Table 4. Variety specific data on the net present value (NPV) ${ }^{1}$ (per ha) ( $4 \%$ discount rate as discounting factor) obtained for apple production in the south, obtained with linear programming (Solver CPLEX). ${ }^{2}$

\begin{tabular}{lccc}
\hline & NPV Mean & NPV Stdev & CV \\
\hline Boskoop HN & 11 & 25 & 2.30 \\
Braeburn HN & 54 & 59 & 1.09 \\
Elstar HN & 19 & 55 & 2.92 \\
Gala HN & 31 & 45 & 1.47 \\
Jonagold HN & 49 & 54 & 1.53 \\
Jonagored HN & 31 & 56 & 1.81 \\
Boskoop HI sub & 2 & 46 & 11.46 \\
Braeburn HI sub & 37 & 44 & 1.24 \\
Elstar HI sub & 10 & 38 & 4.43 \\
Gala HI sub & 22 & 61 & 1.76 \\
Jonagold HI sub & 35 & 45 & 1.74 \\
Jonagored HI sub & 21 & 25 & 2.16 \\
Boskoop FI sub \& HI sub & 3 & 45 & 9.45 \\
Braeburn FI sub \& HI sub & 38 & 41 & 1.19 \\
Elstar FI sub \& HI sub & 10 & 37 & 3.95 \\
Gala FI sub \& HI sub & 22 & 57 & 1.67 \\
Jonagold FI sub \& HI sub & 35 & 42 & 1.62 \\
Jonagored FI sub \& HI sub & 22 & & 1.95 \\
\hline
\end{tabular}

${ }^{1} \mathrm{NPV}$ in $1000 €$.

${ }^{2} \mathrm{HN}=$ hail nets; FI sub $=$ subsidized frost insurance; $\mathrm{HI}$ sub $=$ subsidized hail insurance.

yield and price estimates. In the south apple growers stated lower yields per hectare as well as lower prices regarding direct sale activities. With respect to yield, an overestimation of yield risks might be a source of these divergences. In this context, Menapace et al. (2014) find that farmers, who experienced specific risks during the preceding years, show a significant increase in stated probabilities associated with future risks. In total $28.8 \%$ of the northern apple growers in the survey indicated that the enterprise was severely or more than severely affected due to hail, whereas $48.5 \%$ of the apple growers in the south stated that hail caused serious losses in the past. Thus, bias occurring due to events of the past might be a reasonable explanation. Comparable to the north, the CEs also decline with increasing risk aversion and, again, the decrease is smaller for the insurance-based portfolio. This effect arises from a reduction in variance of CEs when considering 


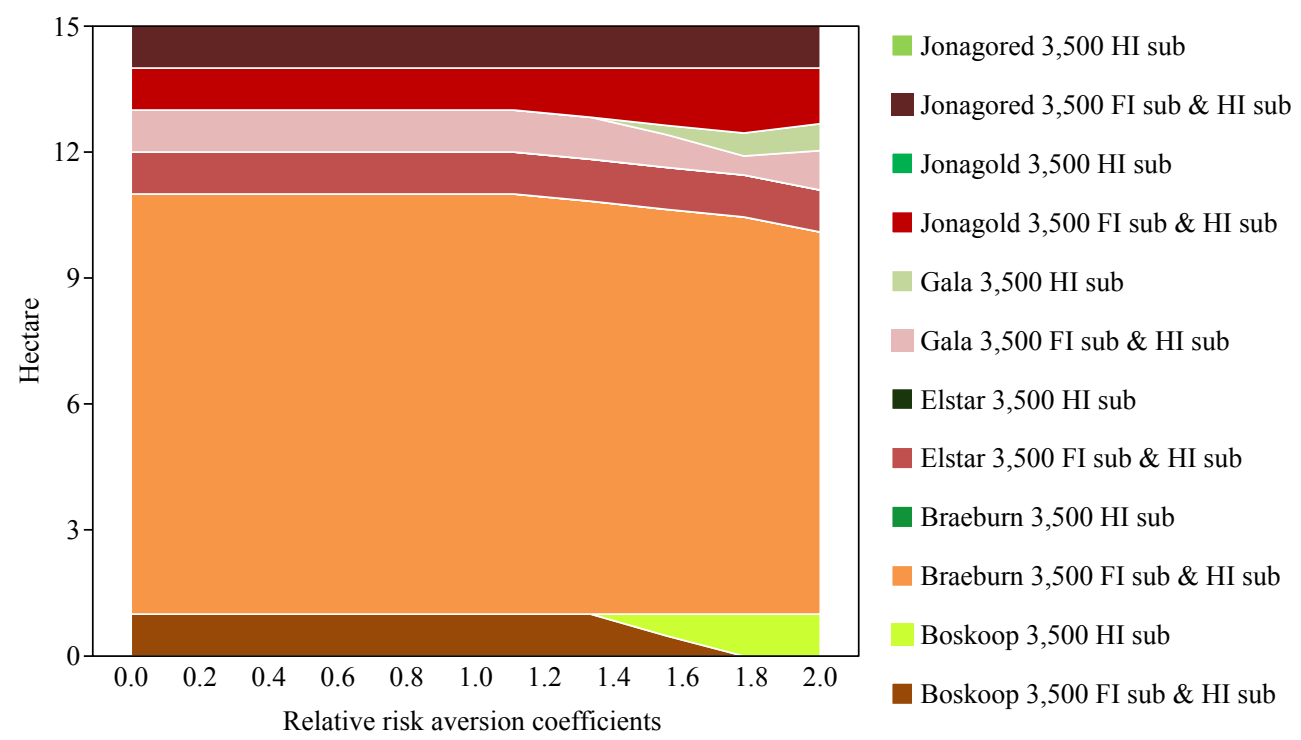

Figure 12. South - Results for FI sub \& HI sub as well as HI sub as RMI and a 4\% discount rate as discounting factor.

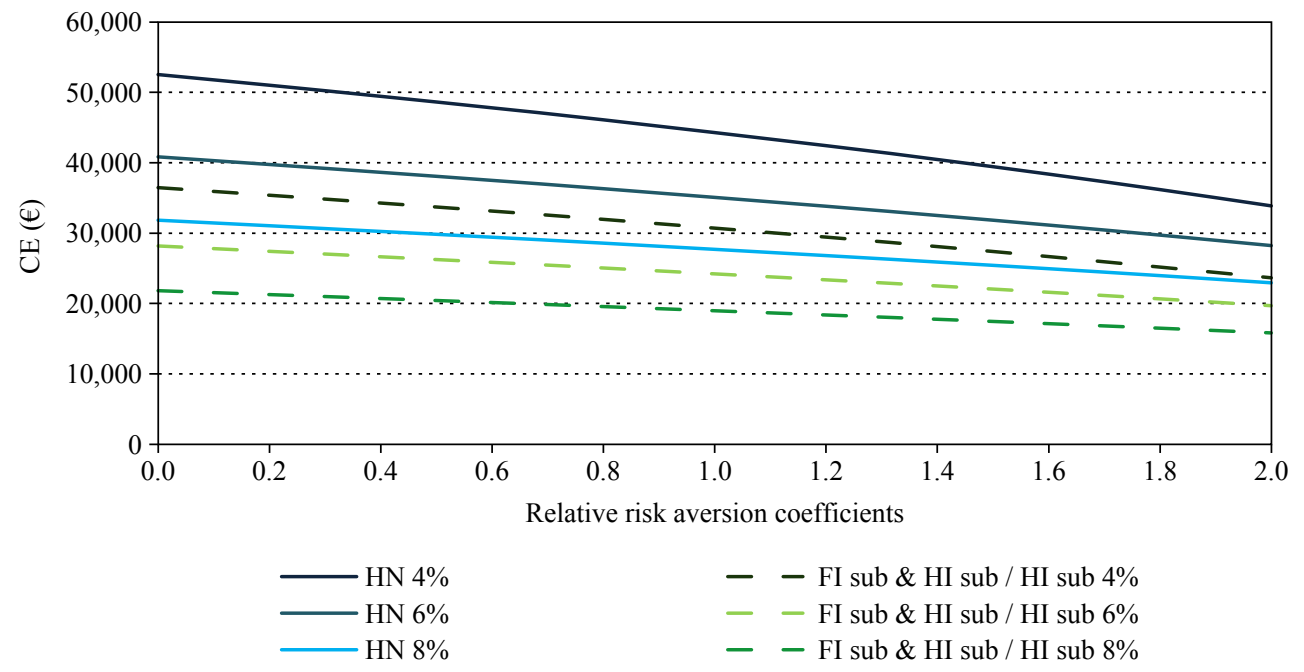

Figure 13. South - Certainty equivalents (CEs) of the portfolios HN and FI sub \& HI sub/HI sub as RMI.

insurances as RMI. Nevertheless, when focusing on the same discounting rates, the related CEs of the insurance-based portfolio are all located below the ones associated with the HN solution. However, the associated annuities, shown in Figure 14, allow a clearer differentiation. The HN solution is always superior compared to the farming strategy based on insurances. In monetary terms, the absence of HN would result in a monetary loss of $1000 €$ per hectare. Similar results are reported in the study of Gandorfer et al. (2016), analyzing the hedging efficiency of $\mathrm{HN}$ and $\mathrm{HI}$ for Bavarian apple orchards in Germany, assuming relative risk aversion ranging from $0-4$. When considering hail damage in 6 of 10 years, indicating high hail risk, $\mathrm{HN}$ are associated with the highest CEs, independent of the apple growers' degree of relative risk aversion. However, HI becomes more attractive for risk averse apple growers with low initial wealth producing on areas with medium hail risk, i.e. 2 of 10 years with hail damage (Gandorfer et al., 2016). Observations in reality supports the plausibility of the results presented in this work, as most of the apple production area in the south is covered with HN. 


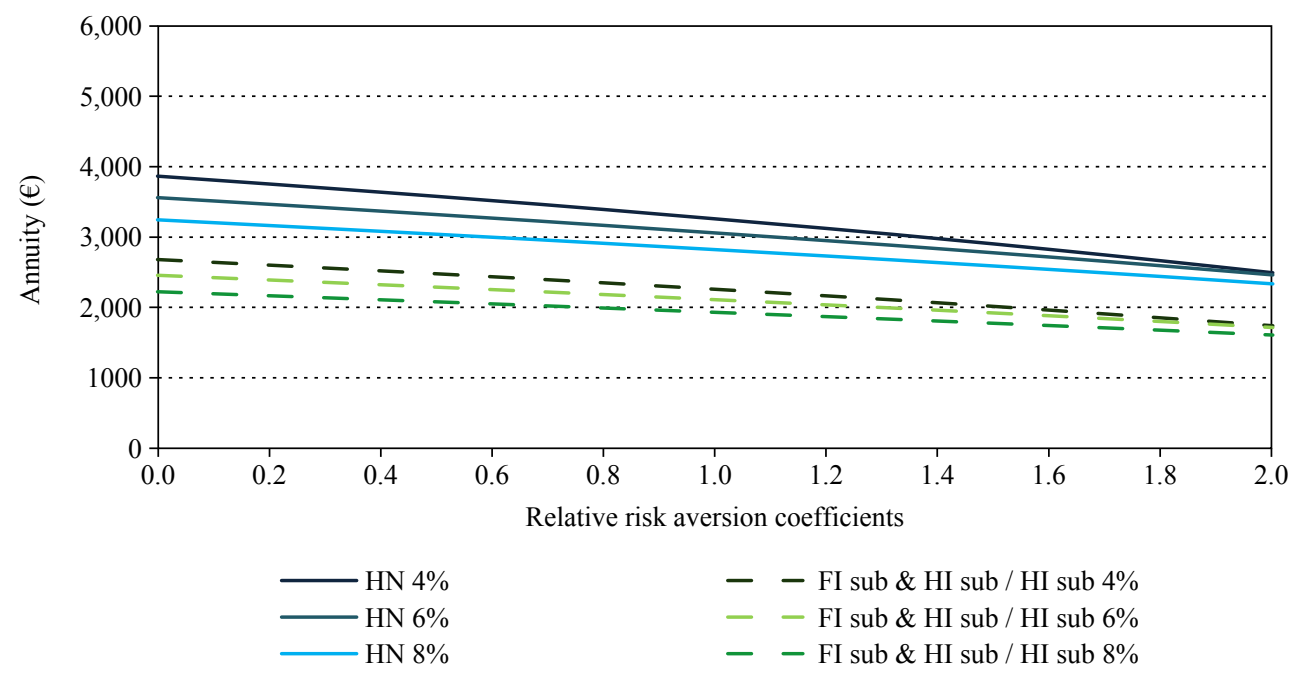

Figure 14. South - Annuities of the portfolios HN and FI sub \& HI sub/HI sub as RMI.

Based on the estimates obtained from both regions, Boskoop is the variety with the least favorable characteristics. In this context, stated yields in the north as well as prices of the quality class extra and one are lower than those of Elstar, whereas yield of Boskoop in the south is higher than for Elstar, which results in increased variable and fixed costs. Furthermore, market prices are slightly below those of Elstar. The sum insured is based on market prices, which also influences the amount of insurance costs, indemnity payments and subsidies. As the market prices of Boskoop are low, indemnity payments and subsidies are less compared to those of other varieties. This explains the proportional decline of the mean NPV for Boskoop when switching from $\mathrm{HN}$ production to insurance solutions as RMI, which is higher in comparison to other varieties. As the mean NPV of Boskoop is low, the CV calculated for HI and FI sub \& HI sub is high (Table 3). Nevertheless, Boskoop together with Gala is the variety, which is included in the portfolio with subsidized hail insurance (Figure 12). One explanation is that for these two varieties the switch from combined frosthail insurance to a single hail insurance causes the lowest loss in terms of mean NPV (Table 4).

Several conclusions referring to the conception of apple production risk models can be deduced from this work. Stronger specifications on variety depended distribution strategies, i.e. sale channels, could represent activities more distinctly. With respect to the models restrictions referring to production area, the minimum production of 1 ha per variety may overestimate the target-amount of selling a broad range of varieties direct to the consumers. Here, a fine graduation of absolute amounts of apples directly sold to the consumers would reflect reality more precisely. In this case, volatile amounts of yield under normal production conditions should be modeled via a change constraint programming. However, it is assumed that in reality apple growers calculate with average yield per hectare, conceding this simplification in the present model.

The utility-valuation is made on discounted cash-flow level, which describes variations of wealth better than on a higher aggregated net present value level. However, the UEP approach does not allow an evaluation of liquidity constraints and therefore no conclusions regarding financing activities can be drawn. This work could be advanced by considering additional hazards, for example human or institutional risks, and farming activities, as tree removal and replanting of orchards or other agricultural activities. In addition, further farm specific restrictions may be introduced, as for example pest management and work peaks during harvest.

\section{Conclusions}

This study addresses the effect of risk attitude on apple growers' production portfolio. Since uncertainty is prevalent in apple production deterministic models are not adequate for determining a long-term strategy. To gain insights into the influence of risk attitude on apple growers' production plan, we developed an expected 
utility model. This model considers different varieties, as well as available risk management instruments (hail nets, hail insurance and irrigation for frost protection) and a hypothetical frost-hail insurance. The calculations are carried out for two different regions of Germany, exposed to different weather-related risks, and using three different discount rates. The analysis reveals that the degree of risk aversion shows only marginal effects on the composition of portfolios and is thus not to be assumed as one of the main drivers regarding diversification in apple production. Nevertheless, at high levels of risk aversion, portfolio composition is influenced. If different RMI strategies are available, they however become part of the portfolio, as can be seen from the results we obtained for the northern part. In this context, the concept of combined frost-hail insurance would especially be interesting for low yielding varieties or for those achieving only low prices. With respect to these, revenue losses occurring without overhead irrigation for frost protection are acceptable and the combined frost-hail insurance allows a diversification of the farming strategy. In the south the production under hail nets remains the most favorable production strategy. Losses occurring without hail nets are not completely compensated by indemnity payments and subsidies. However, as long as the current subsidy schemes are paid, insurances can be a rational choice for apple growers, who operating in uneven terrain or who are not allowed to install hail nets.

\section{Acknowledgement}

Special thanks go to M. Büchele of the Kompetenzzentrum Obstbau-Bodensee (KOB) and M. Görgens of the Obstbauzentrum Jork, who supported us in making contacts to apple farmers. Funding of the research by the Federal Ministry of Education and Research is gratefully acknowledged.

\section{References}

Agrarmarkt Informations-Gesellschaft (AMI). 2013. AMI Marktbilanz Obst. 2013. AMI Agrarmarkt Informations-Gesellschaft mbH, Bonn, Germany.

Ahumada, O. and J.R. Villalobos. 2009. Application of planning models in the agri-food supply chain: a review. European Journal of Operational Research 196(1): 1-20.

Bobojonov, I. and A. Aw-Hassan. 2014. Impacts of climate change on farm income security in Central Asia: an integrated modeling approach. Agriculture, Ecosystems and Environment 188: 245-255.

Bocquého, G. and F. Jacquet. 2010. The adoption of switchgrass and miscanthus by farmers: impact of liquidity constraints and risk preferences. Energy Policy 38(5): 2598-2607.

Bravin, E., A. Kilchenmann and M. Leumann. 2009. Six hypotheses for profitable apple production based on the economic work-package within the ISAFRUIT Project. Journal of Horticultural Science and Biotechnology. ISAFRUIT Special Issue: 164-167.

Buchholz, M. and O. Musshoff. 2014. The role of weather derivatives and portfolio effects in agricultural water management. Agricultural Water Management 146: 34-44.

Catalá, L.P., G.A. Durand, A.M. Blanco and J.A. Bandoni. 2013. Mathematical model for strategic planning optimization in the pome fruit industry. Agricultural Systems 115: 63-71.

Dixit, A.K. and R. Pindyck. 1994. Investment under uncertainty. Princeton University Press, Princeton, NJ, USA.

Dorward, A. 1999. Modelling embedded risk in peasant agriculture: methodological insights from northern Malawi. Agricultural Economics 21: 191-203.

Ermoliev, Y.M., T.Y. Ermolieva, G.J. MacDonald, V.I. Norkin and A. Amendola. 2000. A system approach to management of catastrophic risks. European Journal of Operational Research 122(2): 452-460.

Federal Statistical Office. 2014. Gesamtwirtschaft and Umwelt - Verbraucherpreisindizes - Verbraucherpreise - Statistisches Bundesamt (Destatis). Available at: http://tinyurl.com/y7dno6se.

Frederick, S., G. Loewenstein and T. O'Donoghue. 2002. Time discounting and time preference: A critical review. Journal of economic literature 40: 351-401.

Gandorfer, M., A. Hartwich and V. Bitsch. 2016. Hail risk management in fruit production: anti-hail net versus hail insurance in Germany. Acta Horticulturae 1132: 141-146. 
Hardaker, J.B., R.B.M. Huirne, J.R. Anderson and G. Lien. 2004. Coping with risk in agriculture, $2^{\text {nd }}$ ed. CAB International, Wallingford, UK.

Hoag, D.L. 2010. Applied risk management in agriculture, $1^{\text {st }}$ ed. CRC Press-Taylor and Francis Group, Boca Raton, FL, USA.

Hoffmann, H., F. Langner and T. Rath. 2012. Simulating the influence of climatic warming on future spring frost risk in Northern German fruit production. Acta Horticulturae 957: 289-296.

Holt, C.A. and S.K. Laury. 2002. Risk aversion and incentive effects. American Economic Review 92(5): 1644-1655.

Ihli, H.J., S.C. Maart-Noelck and O. Musshoff. 2014. Does timing matter? A real options experiment to farmers' investment and disinvestment behaviours. Australian Journal of Agricultural and Resource Economics 58(3): 430-452.

Janssen, S. and M.K. van Ittersum. 2007. Assessing farm innovations and responses to policies: A review of bio-economic farm models. Agricultural Systems 94: 622-636.

KTBL. 2010. Obstbau. Betriebswirtschaftliche und produktionstechnische Kalkulationen, $4^{\text {th }}$ ed. Kuratorium für Technik und Bauwesen in der Landwirtschaft e.V. (KTBL), Darmstadt, Germany.

Landesamt für Statistik Niedersachsen. 2017. Erntestatistik online - Ernteergebnisse seit 1991. Available at: http://tinyurl.com/y88hxoce.

Lehmann, N., S. Briner and R. Finger. 2013. The impact of climate and price risks on agricultural land use and crop management decisions. Land Use Policy 35: 119-130.

Lien, G. and J.B. Hardaker. 2001. Whole-farm planning under uncertainty: impacts of subsidy scheme and utility function on portfolio choice in Norwegian agriculture. European Review of Agricultural Economics 28(1): 17-36.

Lien, G., S. Størdal, J.B. Hardaker and L.J. Asheim. 2007. Risk aversion and optimal forest replanting: A stochastic efficiency study. European Journal of Operational Research 181(3): 1584-1592.

Lien, G., J.B. Hardaker, M.A.P.M. Van Asseldonk and J.W. Richardson. 2011. Risk programming analysis with imperfect information. Annals of Operations Research 190(1): 311-323.

Markowitz, H. 2014. Mean-variance approximations to expected utility. European Journal of Operational Research 234(2): 346-355.

Menapace, L., G. Colson and R. Raffaelli. 2013. Risk aversion, subjective beliefs and farmer risk management strategies. American Journal of Agricultural Economics 95(2): 384-389.

Menapace, L., G. Colson and R. Raffaelli. 2014. Farmers' climate change risk perceptions: An application of the exchangeability method. Paper presented at the EAAE 2014 Congress, Ljubljana, Slovenia, 26-29 August 2014, pp. 1-13. Available at: http://tinyurl.com/yar2f9cs.

Meyer, A. 2013. Estimating discount factors for public and private goods and testing competing discounting hypotheses. Journal of Risk and Uncertainty 46(2): 133-173.

Mouron, P. and R.W. Scholz. 2008. Management influence on income risk in an apple production system on Swiss fruit farms. International Journal of Fruit Science 7(4): 47-70.

Ogurtsov, V.A., M.P.A.M. Van Asseldonk and R.B.M. Huirne. 2008. Assessing and modelling catastrophic risk perceptions and attitudes in agriculture: a review. NJAS - Wageningen Journal of Life Sciences 56(1/2): 39-58.

Pandey, S. and J.B. Hardaker. 1995. The role of modelling in the quest for sustainable farming systems. Agricultural Systems 47: 439-450.

Röhrig, M.B.K., B. Hardeweg and W. Lentz. 2018. Efficient farming options for German apple growers under risk - a stochastic dominance Approach. International Food and Agribusiness Management Review 21(1): 101-120.

Senkondo, E.M.M. 2000. Risk attitude and risk perception in agroforestry decisions: the case of Babati, Tanzania. Dissertation, Wageningen University, Wageningen, the Netherlands.

Thomson, G., M. McCaskill, I. Goodwin, G. Kearney and S. Lolicato. 2014. Potential impacts of rising global temperatures on Australia's pome fruit industry and adaptation strategies. New Zealand Journal of Crop and Horticultural Science 42(1): 21-30.

Trigeorgis, L. 1996. Real options. Managerial flexibility and strategy in resource allocation. MIT Press, Cambridge, MA, USA. 
Waibel, H., H. Garming and K. Zander. 2001. Die Umstellung auf ökologischen Apfelanbau als risikobehaftete Investition. Agrarwirtschaft 50(7): 439-450.

Way, R.D. 1995. Pollination and fruit set in fruit crops. Cornell Cooperative Extension Information Bulletin 237, New York, NY, USA.

Winter, F. 2002. Lucas' Anleitung zum Obstbau, 32 ${ }^{\text {nd }}$ ed. Eugen Ulmer, Stuttgart, Germany.

Wolbert-Haverkamp, M. and O. Musshoff. 2014. Are short rotation coppices an economically interesting form of land use? A real options analysis. Land Use Policy 38: 163-174.

Zentrale Markt- und Preisinformationen (ZMP). 1998. ZMP-Marktstatistik. Obst 1998. Absatzmengen und Verkaufserlöse der deutschen Erzeugermärkte. Zentrale Markt- und Preisberichtstelle für Erzeugnisse der Land-, Forst- und Ernährungswirtschaft GmbH, Bonn, Germany.

Zentrale Markt- und Preisinformationen (ZMP). 2002. ZMP-Marktstatistik. Obst 2002. Absatzmengen und Verkaufserlöse der deutschen Erzeugermärkte. Zentrale Markt- und Preisberichtstelle für Erzeugnisse der Land-, Forst- und Ernährungswirtschaft GmbH, Bonn, Germany.

Zentrale Markt- und Preisinformationen (ZMP). 2006. ZMP-Marktstatistik. Obst 2006. Absatzmengen und Verkaufserlöse der deutschen Erzeugermärkte. Zentrale Markt- und Preisberichtstelle für Erzeugnisse der Land-, Forst- und Ernährungswirtschaft GmbH, Bonn, Germany. 
